\title{
Phycocyanin Enhances Secretary IgA Antibody Response and Suppresses Allergic IgE Antibody Response in Mice Immunized with Antigen-Entrapped Biodegradable Microparticles
}

\author{
Chinami NEMOTo-KAWAMURA ${ }^{1}$, Tomohiro HIRAHASHI ${ }^{2}$, Takayuki NAGAI ${ }^{3}$, Haruki YAMAdA ${ }^{3}$, \\ Toshimitsu KATOH ${ }^{2}$ and Osamu HAYASHI ${ }^{1, *}$ \\ ${ }^{1}$ Department of Health and Nutrition, Kagawa Nutrition University, \\ Chiyoda, Sakado, Saitama 350-0288, Japan \\ ${ }^{2}$ Biochemical Division, Dainippon Ink \& Chemicals Inc., Ichihara, Chiba 290-8585, Japan \\ ${ }^{3}$ Kitasato Institute for Life Sciences, Kitasato University, Shirokane, Minato-ku, Tokyo 108-8641, Japan
}

(Received August 21, 2003)

\begin{abstract}
Summary In the present study, we have investigated the effects of phycocyanin, a biliprotein of Spirulina platensis, on mucosal and systemic immune responses and allergic inflammation in $\mathrm{C} 3 \mathrm{H} / \mathrm{HeN}$ and $\mathrm{BALB} / \mathrm{cA}$ mice. To induce the antigen-specific antibodies in the peripheral lymphoid tissues such as Peyer's patches and mesenteric lymph nodes, biodegradable ovalbumin-entrapped poly (DL-lactide-co-glycolide) particles were used as an antigen. Two weeks after the onset of phycocyanin ingestion, mice were immunized with an aqueous ovalbumin (OVA) solution. Starting at one week after the primary immunization, the mice were subjected to oral immunization with the biodegradable OVA microparticles twice a week. IgA, IgE and IgG1 antibodies were determined by ELISA. The OVA microparticles of $4-\mu \mathrm{m}$ diameter successfully induced antigen-specific antibodies. In the mice that received phycocyanin treatment for $6 \mathrm{wk}$, a marked increase in the antigen-specific, as well as the total, IgA antibody level was observed in the Peyer's patches, mesenteric lymph nodes and intestinal mucosa as well as in the spleen cells. Both antigen-specific IgG1 and IgE antibody levels in the serum were suppressed by ingestion of phycocyanin for $8 \mathrm{wk}$. However, inflammation of the small intestine, monitored as vascular permeability by the Evans blueleaking method was reduced by phycocyanin at $6 \mathrm{wk}$, which preceded the suppression of antigen-specific IgG1 and IgE antibody production by $2 \mathrm{wk}$. These results suggest that phycocyanin enhances biological defense activity against infectious diseases through sustaining functions of the mucosal immune system and reduces allergic inflammation by the suppression of antigen-specific IgE antibody.
\end{abstract}

Key Words phycocyanin, biodegradable microparticles, mucosal immune system, secretory $\operatorname{Ig} A$ antibody, IgE antibody

The mucosal surface is constantly exposed to food, microorganisms and other foreign objects that function as extrinsic antigens. The mucosal immune system serves as the frontline of defense, and the secretory $\operatorname{Ig} \mathrm{A}$ plays an important role in preventing allergies and infectious diseases (1).

Spirulina platensis, which belongs to the class Cyanophyceae or Cyanobacteria, is used as a health food because it is rich in high-quality proteins, vitamins and minerals $(2,3)$. Oral intake of Spirulina controls bloodsugar levels and improves hyperlipidemia and anemia $(2,4)$. Ingestion of either intact or a hot water extract of Spirulina promotes phagocytic capacity of macrophages, production of interleukin-1, and both cell growth and antibody production in the spleen of mice $(5,6)$. Moreover, calcium spirulan, one of the components of the hot water extract of Spirulina, can inhibit virus entry (7) and metastasis of melanoma cells to the

\footnotetext{
*To whom correspondence should be addressed.
}

E-mail: hayashi@eiyo.ac.jp lung (8).

Spirulina contains phycocyanin, a blue, 270-kDa photosynthetic pigment protein, which accounts for approximately $15 \%$ of the dry weight of Spirulina (3). We have previously investigated the effect of phycocyanin ingestion on the immune response of the intestinal mucosa, which plays an important role as one of the body's defense mechanisms against food allergies and infectious diseases. Ingestion of phycocyanin promoted production of total $\operatorname{IgA}$ antibody in the intestinal mucosa of the mice immunized with soluble ovalbumin (OVA) as an antigen (9). In Peyer's patches that comprise the peripheral lymphoid tissues, the production of total IgA antibody was also promoted by phycocyanin. However, the antigen-specific $\operatorname{IgA}$ antibodies in both Peyer's patches and mesenteric lymph nodes were undetected, probably because an aqueous solution of OVA was used as an antigen. The aqueous OVA antigen could be too easily degraded in the digestive tract to retain functional antigenicity. An antigen that has been entrapped in biodegradable microparticles may circum- 
vent the problem of antigen degradation (10-12).

In the present study, we focused on the study of immune responses in the intestinal mucosa in mice after ingestion of phycocyanin. OVA entrapped in biodegradable microparticles made of poly (DL-lactide-co-glycolide) was used as an antigen, which successfully induced antigen-specific IgA antibodies in the peripheral lymphoid tissues and enabled us to examine the effects of phycocyanin on the mucosal immune response. IgA antibody responses were monitored in the intestinal mucosa, mesenteric lymph nodes, Peyer's patches and spleen cells. The effects of phycocyanin on type I allergies were studied by measuring serum IgE antibody levels. In addition, the relationship of phycocyanin ingestion to inflammation as a factor in intestinal vascular permeability was also investigated.

\section{MATERIALS AND METHODS}

Preparation of phycocyanin solution. Phycocyanin was extracted from spray-dried Spirulina platensis with $50 \mathrm{~mm}$ sodium-phosphate buffer ( $\mathrm{pH}$ 6.0). The crude extract was partially purified by DE-52 ion-exchange chromatography (13). The eluate was dialyzed against distilled water (DW) and lyophilized. Phycocyanin contents of the resultant powder were over $80 \%$, and the recovery from the crude extract was approximately $6 \%$. The phycocyanin powder was dissolved in DW to a concentration of $0.05 \%$. The solution was then centrifuged, and the supernatant was sterilized by filtration through a 0.20 - $\mu \mathrm{m}$-pore filter.

Preparation of OVA-entrapped microparticles. The OVAentrapped biodegradable microparticles (OVA microparticles) were prepared using the water-in-oil-in-water emulsion solvent evaporation technique according to the method of Jeffery et al. (14).

OVA (Albumin, chicken egg, $5 \times$ crystalline; Calbiochem, San Diego, CA, USA) was dissolved in DW to a concentration of either $7.5 \%$ or $15 \%$, and filter-sterilized. Poly (DL-lactide-co-glycolide, 50 : 50) (PLG; SigmaAldrich, St. Louis, MO, USA) was dissolved in dichloromethane (DCM) to a concentration of 6\%. Polyvinyl alcohol (PVA; Sigma-Aldrich) was dissolved in DW to a concentration of either $5 \%$ or $10 \%$ and filtered.

Two milliliters of aqueous OVA solution and $5 \mathrm{~mL}$ of PLG solution were homogenized in a microhomogenizer (Ultra-Turrax T18; IKA, Nara, Japan) at 4,000 to $10,000 \mathrm{rpm}$ for 5 to $25 \mathrm{~s}$, followed by an additional $50 \mathrm{~mL}$ of aqueous PVA solution and a second homogenization at the same rotation speed and duration as the first homogenization. After stirring for $15 \mathrm{~h}$ to evaporate DCM, the homogenate was centrifuged at $170 \times g$ for $10 \mathrm{~min}$. The sediment was rinsed three times with sterile DW by centrifugation and lyophilized. To observe the shape of microparticles and obtain the average value of their diameter, more than 400 microparticles in each batch were observed by scanning electron microscopy.

Protein contents of OVA microparticles were determined using the method of Jeffery et al. (14). Lyophilized OVA microparticles $(5 \mathrm{mg})$ were dissolved in
$0.1 \mathrm{M} \mathrm{NaOH}$ containing 5\% sodium dodecyl sulfate. The solution was centrifuged, and the amount of protein in the supernatant was measured using a bicinchoninic acid kit (BCA-kit; Sigma-Aldrich).

Animals, immunization grouping and immunization schedule. Four-week-old female $\mathrm{C} 3 \mathrm{H} / \mathrm{HeN}$ mice (CLEA Japan Inc., Tokyo, Japan) were divided into 3 groups of 10 animals each. All experiments were performed under the guidelines of the animal usage committee of Kagawa Nutrition University. OVA antigen solution of $0.5 \mathrm{~mL}$ phosphate-buffered saline (PBS, pH 7.4) containing $0.5 \mathrm{mg}$ of OVA and $1 \times 10^{10}$ of inactivated Bordetella pertussis cells (Wako Pure Chemical Industries, Ltd., Osaka, Japan) as an adjuvant was administered to each animal through the intraperitoneal route for the primary immunization. For oral administration, the OVA microparticles were suspended in $0.5 \mathrm{~mL}$ of PBS so that each animal was given $1 \mathrm{mg}$ of OVA antigen in each administration. All animals were fed standard laboratory chow (Oriental Yeast Co., Tokyo, Japan) ad libitum and housed at a temperature of $25 \pm 1^{\circ} \mathrm{C}, 40-50 \%$ relative humidity, and a $12 \mathrm{~h}$-light period from 8:00 to 20:00.

The schedules for phycocyanin feeding and OVA-antigen administration were as follows.

OVA-phycocyanin group: The animals were given sterile $0.05 \%$ phycocyanin solution ad libitum for $2 \mathrm{wk}$ prior to the primary immunization, and then a suspension of OVA microparticles was administered orally twice a week for $3 \mathrm{wk}$ starting at one week after the primary immunization. The period of the OVA-microparticle administration was determined by monitoring OVAspecific IgA antibody levels in the feces, which began to increase at $2 \mathrm{wk}$ after the OVA-microparticle administration. The animals were also given phycocyanin solution continuously instead of drinking DW during the entire $6 \mathrm{wk}$ experimental period.

OVA- $\mathrm{H}_{2} \mathrm{O}$ group: The animals were given sterile DW ad libitum, but without phycocyanin. The primary and oral immunizations were the same as for the OVA-phycocyanin group (OVA-Phyc group).

PBS- $\mathrm{H}_{2} \mathrm{O}$ group (control group): The animals were given sterile DW without phycocyanin ad libitum but no other experimental treatment. PBS was used instead of OVA antigen solution or OVA-microparticle suspension.

The three groups of mice consumed almost the same volume of drinking water, that is, $2.3 \mathrm{~mL}$ per mouse per day on average, which is equivalent to approximately $57.5 \mathrm{mg} / \mathrm{kg}$ body weight of the ingested phycocyanin. During the preliminary phycocyanin ingestion period, neither diarrhea nor soft stool was observed and the weight gains of mice were identical in all 3 groups.

$\mathrm{BALB} / \mathrm{cA}$ mice (4-wk-old female; CLEA Japan Inc.), which have been often used for the study of allergies such as food allergies and bronchial asthma, were also used to confirm the results on OVA-specific IgG1 and $\mathrm{IgE}$ in the serum of $\mathrm{C} 3 \mathrm{H} / \mathrm{HeN}$ mice. Phycocyanin was given for 6 or $8 \mathrm{wk}$ to the mice. The other experimental conditions were the same as those described for the 
treatments of $\mathrm{C} 3 \mathrm{H} / \mathrm{HeN}$ mice.

Preparation of serum and small intestine mucous.

Serum: After the final week of phycocyanin ingestion, blood samples were collected from the artery in the left inguinal region of the ether-anesthetized mice and the serum was separated by centrifugation.

Small intestine mucous: After collecting the blood, the entire small intestine from the duodenum to the ileum was excised and severed, on ice, in the longitudinal direction. After rinsing with ice-chilled PBS to remove the intestinal contents, the mucous was gently scraped off from the inner surface of the severed intestine. The isolated mucous ( $0.5 \mathrm{~g}$ of wet weight) was homogenized in $2 \mathrm{~mL}$ of cold PBS, and the homogenate was centrifuged at $40,000 \times g$ for $20 \mathrm{~min}$ to obtain the supernatant.

Culture supernatants of spleen, mesenteric lymph node and Peyer's patch cells. After collecting the blood, the spleen, mesenteric lymph nodes and Peyer's patches were excised under an aseptic condition. Each specimen was aseptically suspended in Hank's balanced salt solution (HBSS; Gibco Co., Grand Island, NY, USA), and the cells were gently dissociated using a homogenizer. The cell suspensions were centrifuged with refrigeration for $5 \mathrm{~min}$ at $1,300 \times \mathrm{g}$. Spleen cell preparation was treated with $0.16 \mathrm{M} \mathrm{NH}_{4} \mathrm{Cl}$ in $0.17 \mathrm{M}$ Tris-HCl buffer ( $\mathrm{pH} 7.6$ ) to remove contaminating erythrocytes. After rinsing the cells 3 times with HBSS by centrifugation, each specimen was adjusted to $2 \times 10^{6}$ cells $/ \mathrm{mL}$ by dilution with RPMI 1640 (Nikken Biomedical Laboratory, Kyoto, Japan) containing 10\% FBS (Gibco). Ten microliters of 10\% FBS/RPMI 1640 containing $5 \mu \mathrm{g}$ OVA was added to $1 \mathrm{~mL}$ of each of the cell suspensions, which were then cultured for $4 \mathrm{~d}$ in a $\mathrm{CO}_{2}$ incubator. Following the incubation period, the culture supernatants were collected by filtration $(0.20 \mu \mathrm{m})$.

Determination of antibody levels by ELISA. IgA and IgG1 antibodies were measured using the method of Takahashi et al. (15). Wells of microtiter plates were coated either with rabbit anti-mouse IgA or IgG1 (Zymed Lab. Inc., South San Francisco, CA, USA) for total antibody assay, or with OVA solution for assay of antigen-specific antibody. Horseradish peroxidase-conjugated goat anti-mouse IgA or IgG1 (Zymed) was used as the secondary antibody. Mouse myeloma IgA or IgG1 (Zymed) was used as a standard for the total antibody. Absorbance at $492 \mathrm{~nm}$ was measured with a microplate reader. Assays of each sample were performed in duplicate.

Antigen-specific IgE antibody. Measurement of IgE antibody was performed using the method described previously by Nagai et al. (16). Briefly, wells of microtiter plates were coated with a rat anti-mouse $\operatorname{IgE}$ (Pharmingen Inc., Omaha, NE, USA), followed by incubation for $3 \mathrm{~h}$ at $37^{\circ} \mathrm{C}$. Blocking was performed for $1 \mathrm{~h}$ at $37^{\circ} \mathrm{C}$ with $1 \%$ skim milk. The diluted serum sample was added, followed by an overnight incubation at room temperature. The resulting mixture was then incubated with biotin-labeled OVA for $1 \mathrm{~h}$ at room temperature. Streptavidin-conjugated $\beta$-galactosidase (Cal- biochem) was added, followed by incubation for $1 \mathrm{~h}$ at room temperature. The enzyme substrate, 4-methylumbelliferyl $\beta$-D-galactopyranoside (Sigma-Aldrich) was added, followed by incubation for $3 \mathrm{~h}$ at $37^{\circ} \mathrm{C}$. Fluorescence (Ex. 355 nm, Em. 460 nm) was measured with a spectrofluorometer. Assays of each sample were performed in duplicate.

Intestinal vascular permeability test using pigment-leakage method. Intestinal vascular permeability was examined according to the method of Kataoka et al. (17) with minor modifications. A solution of $0.5 \%$ Evans blue (Wako Pure Chemical Industries) in saline was filtered through a $0.2-\mu \mathrm{m}$ filter for sterilization. After injecting $0.2 \mathrm{~mL}$ of the Evans blue solution into the caudal vein of each $\mathrm{C} 3 \mathrm{H} / \mathrm{HeN}$ mouse $(5$ mice per group) in the absence of anesthesia at the completion of the OVA-antigen administration schedule, $0.5 \mathrm{~mL}$ of $0.1 \%$ OVA aqueous solution was immediately administered orally. Thirty minutes later, the animals were sacrificed by cervical dislocation, and the entire small intestine was excised. The isolated intestine was transferred to a tube containing $4 \mathrm{~mL}$ of $100 \%$ formamide (Wako Pure Chemical Industries) and incubated for $3 \mathrm{~d}$ at $37^{\circ} \mathrm{C}$. The supernatant was collected by centrifugation, and the absorbance at $637 \mathrm{~nm}$ was measured with a colorimeter.

Statistical analysis. StatView J-5.0 (SAS Institute Inc., Cary, NC, USA) software was used for statistical analysis. Analysis of variance and multiple comparison tests were used for comparisons among the 3 groups, and Fisher's PLSD was used for the multiple comparison test.

\section{RESULTS}

\section{OVA microparticles}

The antibody response after administration of OVAentrapped microparticles of $1-2 \mu \mathrm{m}$ in diameter was not different from that of animals immunized with aqueous solutions of OVA. Therefore, conditions were explored for obtaining slightly larger microparticles. The diameter of the microparticles tended to depend on both the rotating speed of homogenization and the concentration of PVA composing the outermost layer of microparticles, when the concentration of PLG was kept at $6 \%(14)$. Four examples of the conditions examined are shown in Table 1. The homogenization at 6,000 rpm increased the particle diameter approximately by $1 \mu \mathrm{m}$ as compared with that at 8,000 rpm (columns A and B). Homogenization speeds lower than 6,000 rpm tended to increase pitted or collapsed particles and induce sheet-like structures, and a speed higher than $8,000 \mathrm{rpm}$ decreased the rate of particle production, in addition to the decrease in particle size. When PVA concentration was increased, the resulting particles became larger (columns $\mathrm{A}$ and $\mathrm{C}$ ). OVA concentrations did not affect the particle size (columns $\mathrm{C}$ and D).

When examined, the effects of the microparticle size on the mucosal responses using microparticles prepared by the conditions A-D (Table 1), microparticles with $4-\mu \mathrm{m}$ diameter were most effective in inducing 
Table 1. Conditions for preparation of microparticles of varying diameter.

\begin{tabular}{|c|c|c|c|c|c|c|}
\hline \multirow{2}{*}{ Condition } & \multirow{2}{*}{ OVA } & \multirow{2}{*}{ PLG/DCM } & \multicolumn{2}{|c|}{ PVA } & \multirow{2}{*}{$\begin{array}{l}\text { Homogenizing } \\
\text { revolution }(10 \mathrm{~s})\end{array}$} & \multirow{2}{*}{$\begin{array}{l}\text { Diameter of particles } \\
(\mu \mathrm{m})\end{array}$} \\
\hline & & & $5 \%$ & $10 \%$ & & \\
\hline A & $7.5 \% / 2 \mathrm{~mL}$ & $300 \mathrm{mg} / 5 \mathrm{~mL}$ & - & $50 \mathrm{~mL}$ & $8.000 \mathrm{rpm}$ & $4.0 \pm 1.0$ \\
\hline B & $7.5 \% / 2 \mathrm{~mL}$ & $300 \mathrm{mg} / 5 \mathrm{~mL}$ & - & $50 \mathrm{~mL}$ & $6,000 \mathrm{rpm}$ & $5.2 \pm 1.7$ \\
\hline $\mathrm{C}$ & $7.5 \% / 2 \mathrm{~mL}$ & $300 \mathrm{mg} / 5 \mathrm{~mL}$ & $50 \mathrm{~mL}$ & - & $8.000 \mathrm{rpm}$ & $2.8 \pm 1.1$ \\
\hline $\mathrm{D}$ & $15.0 \% / 2 \mathrm{~mL}$ & $300 \mathrm{mg} / 5 \mathrm{~mL}$ & $50 \mathrm{~mL}$ & - & $8,000 \mathrm{rpm}$ & $2.9 \pm 1.1$ \\
\hline
\end{tabular}

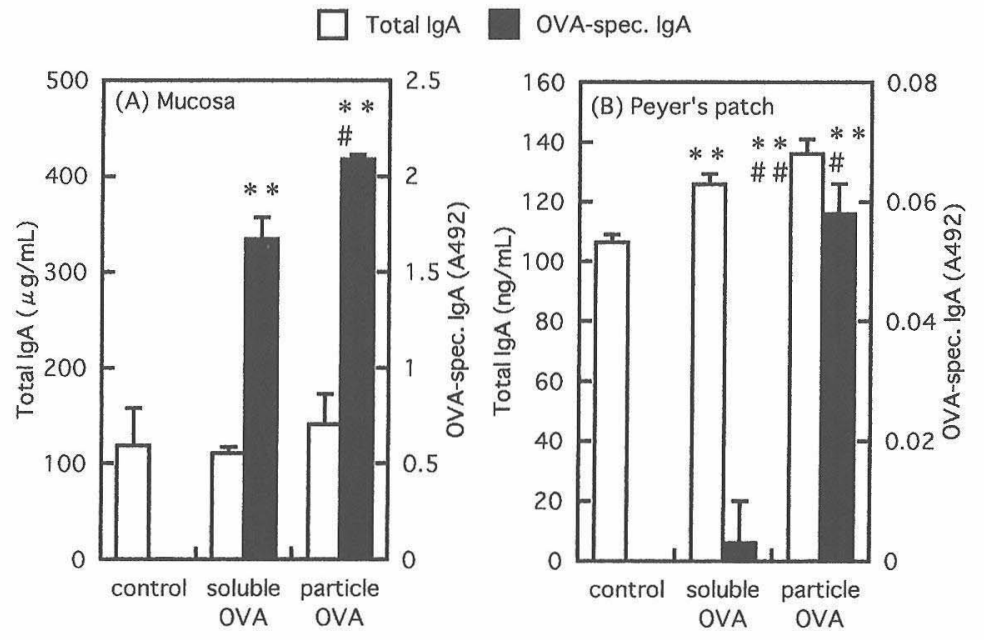

Fig. 1. Total and OVA-specific IgA antibody levels in the intestinal mucosa (A) and Peyer's patch (B) of C3H/HeN mice after oral immunization with either an aqueous OVA solution (soluble OVA) or OVA microparticles (particle OVA). In this experiment, either soluble OVA or particle OVA was administered to the $\mathrm{C} 3 \mathrm{H} / \mathrm{HeN}$ mice for $7 \mathrm{wk}$ for the oral immunization starting at one week after the primary immunization. The other experimental conditions were the same as in phycocyaniningestion experiments. PBS was used instead of OVA for controls. Values of each antibody level are expressed as mean \pm SD $(n=6) .{ }^{* *} p<0.01$ compared with the control and ${ }^{\#} p<0.05{ }^{\# \#} p<0.01$ compared to the soluble OVA.

IgA production in the intestinal mucosa and the culture supernatant of Peyer's patches of $\mathrm{C} 3 \mathrm{H} / \mathrm{HeN}$ mice treated with OVA-microparticles for $7 \mathrm{wk}$ (Fig. 1). The OVA-specific IgA antibody level in both tissues was significantly higher in the mice immunized with the OVA microparticles than those immunized with soluble OVA. Especially, a remarkable increase in the OVA-specific $\operatorname{IgA}$ antibody level was observed in the culture supernatant of Peyer's patch cells (Fig. 1B). In both the intestinal mucosa and the culture supernatant of Peyer's patch cells, total IgA antibody level induced by the OVA microparticles was also higher than that by the soluble OVA (Fig. 1A and B). Because the microparticles with 4$\mu \mathrm{m}$ diameter seemed suitable for studying mucosal immune response, they were used in the subsequent experiments. In the batches prepared by condition A shown in Table 1, microparticles were spherical, and their surface was smooth (Fig. 2). There was no evidence of pitted or collapsed microparticles. More than $60 \%$ of the total number of microparticles had a diameter of $3.5-4.4 \mu \mathrm{m}$, and $10 \mathrm{mg}$ of microparticles contained approximately $1.5 \mathrm{mg}$ of OVA.

Effects of phycocyanin on tissue antibody levels

IgA antibody levels in the culture supernatants of lymphoid organs and the intestinal mucosa. In the culture supernatants of the Peyer's patch and mesenteric lymph

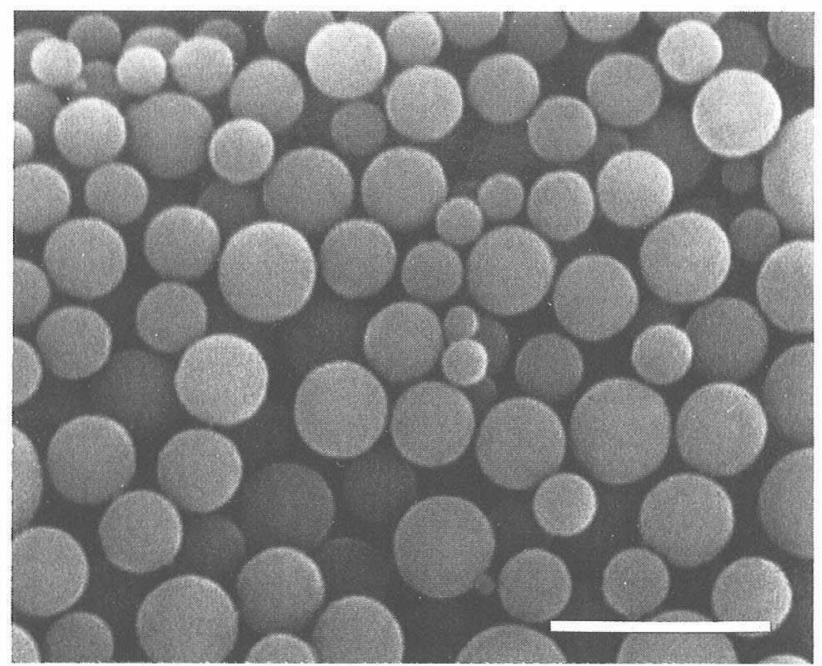

Fig. 2. Scanning electron micrograph of OVA microparticles. In the batch, microparticles having a diameter of $3.5-4.4 \mu \mathrm{m}$ accounted for approximately $60 \%$ of the total number of microparticles counted, and the average diameter was $4 \mu \mathrm{m}$. Scale bar: $10 \mu \mathrm{m}$. 


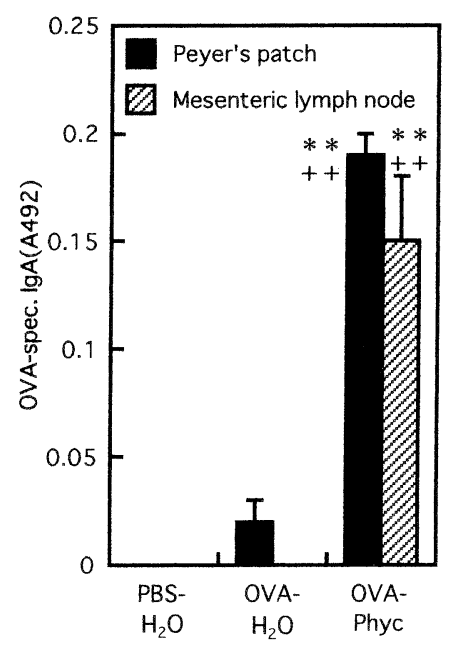

Fig. 3. OVA-specific IgA antibody levels in the cell-culture supernatants from Peyer's patches and mesenteric lymph nodes in the $\mathrm{C} 3 \mathrm{H} / \mathrm{HeN}$ mice treated with phycocyanin for $6 \mathrm{wk}$. Values of each antibody level are expressed as mean $\pm \mathrm{SD}(n=5)$. ${ }^{* *} p<0.01$ compared to PBS- $\mathrm{H}_{2} \mathrm{O}$ and ${ }^{++} p<0.01$ compared to OVA- $\mathrm{H}_{2} \mathrm{O}$.

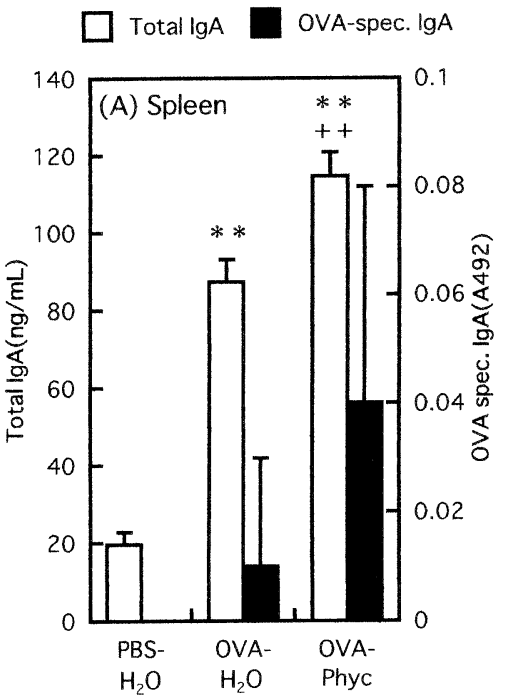

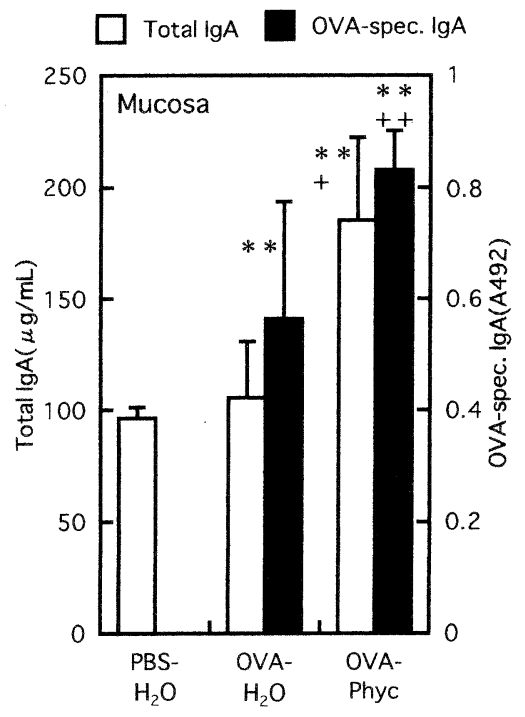

Fig. 4. Total and OVA-specific IgA antibody levels in the intestinal mucosa of the $\mathrm{C} 3 \mathrm{H} / \mathrm{HeN}$ mice treated with phycocyanin for $6 \mathrm{wk}$. Values of each antibody level are expressed as mean $\pm \mathrm{SD}(n=5) .{ }^{* *} p<0.01$ compared to PBS- $\mathrm{H}_{2} \mathrm{O}$ and ${ }^{+} p<0.05,{ }^{++} p<0.01$ compared to OVA$\mathrm{H}_{2} \mathrm{O}$.

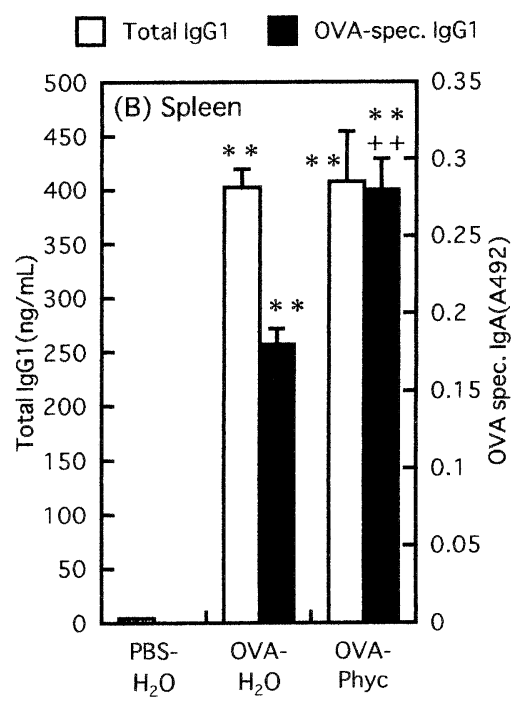

Fig. 5. Total and OVA-specific IgA and IgGI antibody levels in the cell-culture supernatants of spleens from the $\mathrm{C} 3 \mathrm{H} / \mathrm{HeN}$ mice treated with phycocyanin for 6 wk. Values of each antibody level are expressed as mean \pm SD $(n=5)$. ${ }^{* *} p<0.01 \mathrm{com}-$ pared to $\mathrm{PBS}-\mathrm{H}_{2} \mathrm{O}$ and ${ }^{++} p<0.01$ compared to OVA- $\mathrm{H}_{2} \mathrm{O}$.

node cells which were isolated from the $\mathrm{C} 3 \mathrm{H} / \mathrm{HeN}$ mice treated with phycocyanin for $6 \mathrm{wk}$, high levels of OVAspecific IgA antibody were observed (Fig. 3). The antibody level was nearly 8 times higher than that of OVA$\mathrm{H}_{2} \mathrm{O}$ group in the Peyer's patches. In the mesenteric lymph nodes, in particular, the antibody was detected only in the OVA-Phyc group. In the intestinal mucosa, both total and OVA-specific IgA antibody levels of the OVA-Phyc group, which was treated with phycocyanin for $6 \mathrm{wk}$, were highest among the three groups, and were significantly higher than that of the OVA- $\mathrm{H}_{2} \mathrm{O}$ group (Fig. 4). In the culture supernatant of the spleen, the OVA-Phyc group demonstrated the highest levels of antigen-specific and total IgA antibodies (Fig. 5A).

Compared with those 3 wk treatments with the OVA microparticles alone, $7 \mathrm{wk}$ treatment with the OVA microparticles produced much higher levels of OVA-specific IgA antibody in both Peyer's patches and intestinal mucosa, and total IgA antibody in the mucosa (Figs. 1, 3 , and 4).

IgG1 and IgE antibodies in the spleen and the serum. Both OVA-specific IgG1 (Fig. 6A) and IgE antibody (Fig. $6 \mathrm{~B})$ levels in the serum of the OVA-Phyc group in $\mathrm{C} 3 \mathrm{H} /$ HeN mice, which was treated with phycocyanin for 6 wk, were almost the same as those of the OVA- $\mathrm{H}_{2} \mathrm{O}$ group. Total IgG1 antibody levels in the culture supernatants of the spleen and in the serum were not affected by phycocyanin (Fig. 5B and 6A). In the culture supernatant of the spleen cells, however, the OVA-specific IgG1 antibody level of the OVA-Phyc group was signifi- 


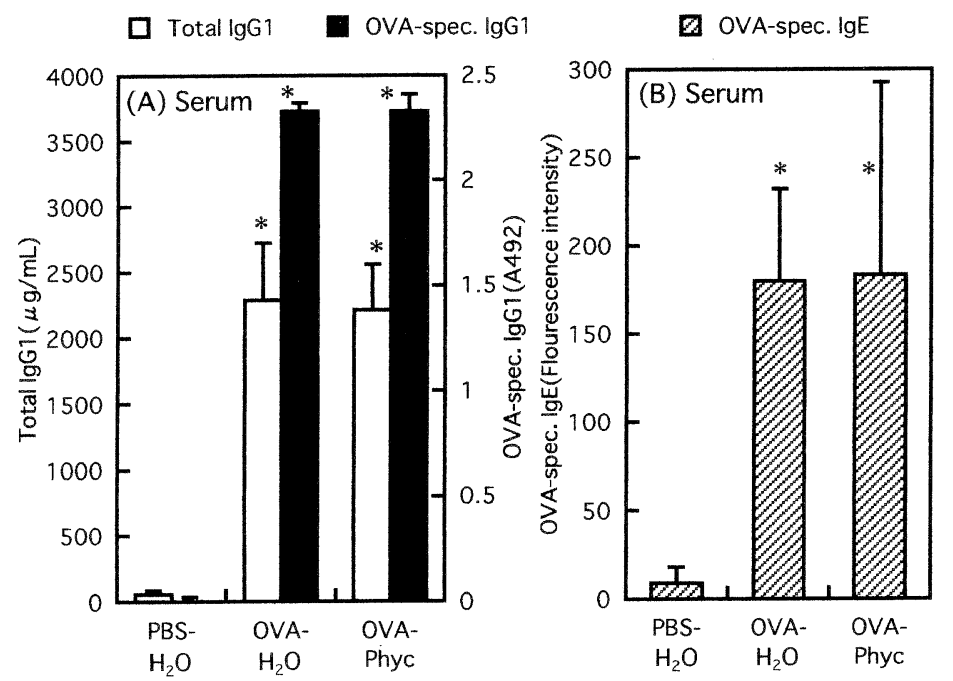

Fig. 6. Total and OVA-specific IgGI and IgE antibody levels in the serum from the $\mathrm{C} 3 \mathrm{H} / \mathrm{HeN}$ mice treated with phycocyanin for $6 \mathrm{wk}$. Values of each antibody level are expressed as mean $\pm \mathrm{SD}(n=5)$. ${ }^{*} p<0.05$ compared to PBS- $\mathrm{H}_{2} \mathrm{O}$.

OVA-spec. $\lg 1$

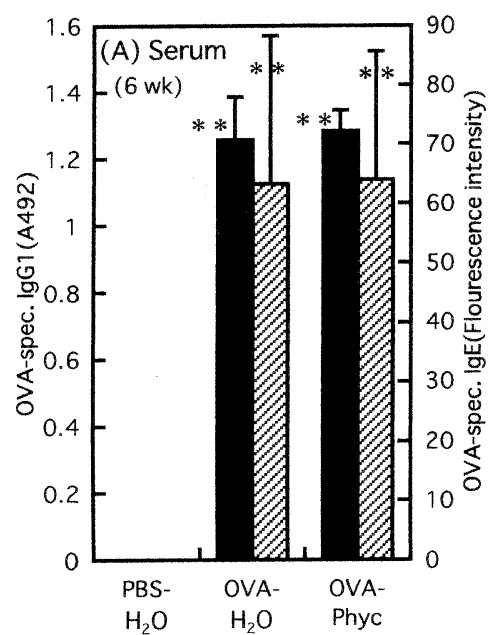

Z OVA-spec. IgE

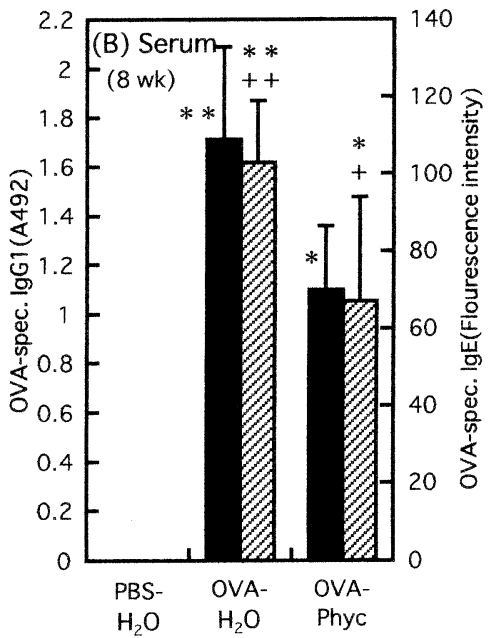

Fig. 7. OVA-specific IgG1 and IgE antibody levels in the serum of the BALB/cA mice treated with phycocyanin for 6 or $8 \mathrm{wk}$. (A) $6 \mathrm{wk}$ and (B) $8 \mathrm{wk}$. Values of each antibody level are expressed as mean $\pm \operatorname{SD}(n=6) . * * *<<0.01$ compared to PBS$\mathrm{H}_{2} \mathrm{O}$ and ${ }^{+} p<0.05,{ }^{++} p<0.01$ compared to OVA- $\mathrm{H}_{2} \mathrm{O}$.

cantly higher than that of the OVA- $\mathrm{H}_{2} \mathrm{O}$ group (Fig. 5B). The levels of both total and OVA-specific IgG1 antibodies in the culture supernatants of mesenteric lymph nodes and Peyer's patch cells were below the detection limit (data not shown).

Effects of phycocyanin on both IgG1 and IgE antibody levels in the serum were also examined using BALB/cA mice. In the mice that were immunized with OVA microparticles and treated with phycocyanin for $6 \mathrm{wk}$ (Fig. 7A), both OVA-specific IgG1 and IgE levels in the serum were not different form those in the OVA- $\mathrm{H}_{2} \mathrm{O}$ group, as observed in the $\mathrm{C} 3 \mathrm{H} / \mathrm{HeN}$ mice (Fig. 6). When phycocyanin treatment was extended to $8 \mathrm{wk}$, however, both serum OVA-specific IgG1 and IgE antibody levels were significantly decreased, as compared with the OVA- $\mathrm{H}_{2} \mathrm{O}$ group (Fig. $7 \mathrm{~B}$ ). In the $\mathrm{BALB} / \mathrm{cA}$ mice, both total and antigen-specific IgA antibody levels in the mucosa were higher in the OVA-Phyc group than those in the OVA- $\mathrm{H}_{2} \mathrm{O}$ group in both 6 and 8 wk treatments

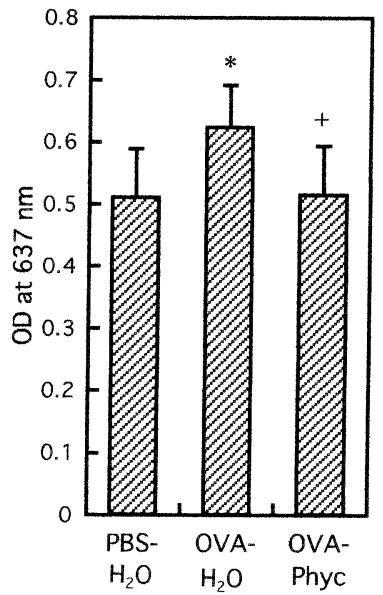

Fig. 8. Intestinal vascular permeability in the $\mathrm{C} 3 \mathrm{H} / \mathrm{HeN}$ mice treated with phycocyanin for $6 \mathrm{wk}$. Vascular permeability was determined by Evans blue-leakage method. Optical density measured at $637 \mathrm{~nm}$ is expressed as mean $\pm \mathrm{SD}(n=5) .{ }^{*} p<0.05$ compared to PBS- $\mathrm{H}_{2} \mathrm{O}$ and ${ }^{+} p<0.05$ compared to OVA- $\mathrm{H}_{2} \mathrm{O}$. 
with phycocyanin (data not shown).

Intestinal vascular permeability

Inflammation in the small intestine of $\mathrm{C} 3 \mathrm{H} / \mathrm{HeN}$ mice was examined using vascular permeability to Evans blue. As shown in Fig. 8, phycocyanin ingestion for 6 wk (OVA-Phyc group) lowered the leakage of the dye from the intestine to the same level as that of the PBS$\mathrm{H}_{2} \mathrm{O}$ control group.

\section{DISCUSSION}

In the previous study using an aqueous solution of OVA as an antigen, we failed to induce an antigen-specific IgA antibody in Peyer's patches and mesenteric lymph nodes that comprise a major part of the mucosal immune system (9). In the present study, as a result of using antigen-entrapped microparticles, antigen-specific IgA antibody was successfully induced in those tissues. Antigen-entrapped microparticles may be a useful tool to study the mucosal immune responses. Challacombe et al. (12) showed that microparticles of $3 \mu \mathrm{m}$ diameter activate both mucosal and systemic immunity in mice. Uchida et al. (18) reported that among several antigen-entrapped microparticles with diameters ranging from 1.3 to $14.0 \mu \mathrm{m}$, microparticles with a $4.0-\mu \mathrm{m}$ diameter result in the greatest increase in serum antigen-specific IgG1 antibody levels in mice. We reported in the previous paper that microparticles having a diameter of approximately $4 \mu \mathrm{m}$ exhibit strong adhesion to Peyer's patches (19). Microparticles with this size, in the present study, induced a remarkable increase in OVA-specific IgA antibody in the mucosal system. Therefore our data are consistent with the idea that there is an appropriate particle size that renders the microparticles effective. In addition to the enhancement of the mucosal antibody response, the OVA microparticles increased in both total IgA and IgG1 antibody levels in the spleen and the serum (Figs. 5, 6A, and 7A), as well as the OVA-specific antibody. This suggests that the enhancement of the systemic immune response as well as the local immune response in mucous is caused by the particle antigen.

A marked increase in OVA-specific IgA antibody induced by phycocyanin was observed in the intestinal mucosa, and in the Peyer's patches and mesenteric lymph nodes, which comprise a major part of gut-associated lymphoid tissues (GALT), suggesting that phycocyanin stimulates the inductive sites of the GALT to induce antigen-specific IgA antibody. Contrary to OVAspecific IgA antibody, OVA-specific IgE and IgG1 antibodies were decreased by the ingestion of phycocyanin. Such an antagonistic relationship between both antigen-specific IgG and IgE antibodies to an antigen-specific IgA antibody is consistent with a report by Tokuyama et al. (20), in which they reported that mice treated simultaneously with retinoic acid and interleukin-5 (IL-5) enhance $\operatorname{IgA}$ antibody production as a result of enhancing the class switch of $\mathrm{B}$ cells to $\operatorname{IgA-}$ antibody-producing precursor cells, while IgG1 antibody is strongly inhibited. The antagonistic antibody behavior produced by phycocyanin suggests that phyco- cyanin exerts its inhibitory effects against allergy via at least two ways: amplification of $\operatorname{Ig}$ A production in the mucosal immunity to defend against the invasion of allergens, and suppression of IgE and IgG1 production in the systemic immunity to minimize excessive responses to allergens. IL- 6 and IL-10 are also known to be involved in the class switching to IgA-antibody-producing precursor cells (21). The isotype class switching to IgA antibody is mediated by TGF- $\beta$, while switching to IgG1 and IgE antibodies is induced by IL-4 (21). These cytokines may also be involved in the promotion of $\operatorname{IgA}$ antibody production and/or the inhibition of IgG1 and IgE antibody production by phycocyanin ingestion. Further experimentation is necessary to verify this concept. In the serum and the cultured spleen cells responsible for the systemic immune system, total IgG1-antibody response in both tissues was not affected by phycocyanin. Antigen-specific IgG1 level, however, did not behave parallel in these tissues, where the antibody level in the serum was not increased, but production of the antibody was enhanced by phycocyanin in the spleen cells (Figs. 5B and 6A). In the spleen cells, phycocyanin may enhance their antibody response via production of IL- 4 and/or increase in the population of IL-4-forming cells since IL-4 production is stimulated in the cultured spleen cells by antigen treatment (22), but the amplification of antibody response by phycocyanin in the spleen cells appears to be not so large as to alter the antigen-specific antibody level in the serum.

In the previous papers, we reported that neither Spirulina-extract nor phycocyanin ingestion for $5 \mathrm{wk}$ affected $\operatorname{IgE}$ antibody response in $\mathrm{C} 3 \mathrm{H} / \mathrm{HeJ}$ mice, while IgA response in the mucosa was enhanced significantly $(5,9)$. In the present study for both $\mathrm{C} 3 \mathrm{H} / \mathrm{HeN}$ and $\mathrm{BALB} / \mathrm{cA}$ mice, serum OVA-specific IgE, as well as OVAspecific IgG1 antibody response to phycocyanin was not affected by a 6 wk treatment with phycocyanin. However, further prolongation of phycocyanin treatment up to 8 wk produced significant suppression of OVA-specific IgE levels in BALB/cA mice, as compared with OVA- $\mathrm{H}_{2} \mathrm{O}$ group (Fig. 7B). This suggests that the prolongation of phycocyanin treatment contributes to the suppression of OVA-specific IgE antibody response, because the behavior of other antibodies was similar among the strains. Another possibility that must be considered is the difference of the susceptibility to phycocyanin among the strains. That is, BALB/cA mice may be more susceptible to phycocyanin, resulting in the enhancement of suppressor T cells or Th1 functions and/or suppression of the Th2 function. To this day, however, there has been no supportive evidence to back this claim.

Remirez et al. (23) reported that in rats phycocyanin prevents allergic dermatitis by inhibiting the release of histamine caused by compound 48/80, a histamine releaser. Romay et al. (24) also reported that phycocyanin administration before application of arachidonic acid prevents the inflammatory edema in the ears of mice, reduces the production of prostaglandin E2 and leukotriene B4, and also inhibits the activity of cyclooxygenase, an enzyme that synthesizes prostaglandins 
from arachidonic acid in the mast cells. In the present study, intestinal vascular permeability in $\mathrm{C} 3 \mathrm{H} / \mathrm{HeN}$ mice was decreased significantly by a 6 -week treatment with phycocyanin, and the vascular permeability decrease proceeded by $2 \mathrm{wk}$ the suppression of antigenspecific IgE antibody that was observed at 8 wk of phycocyanin ingestion. This suggests that phycocyanin may alleviate the inflammation independent of an IgE antibody. Specifically, phycocyanin may suppress the inflammation through a process that occurs prior to the activation of the system that results in suppression of the antigen-specific antibody production.

The results of the present study have revealed that phycocyanin amplifies the mucosal immune response, particularly the mucosal IgA antibody response, inhibits the production of antigen-specific IgE antibodies, and reduces allergic inflammation. Spirulina products containing phycocyanin are not only useful dietary supplements, but also strengthen the defense mechanisms against infectious diseases, food allergies and other inflammatory diseases.

\section{REFFERENCES}

1) Brandtzaeg P, Farstad IN, Haraldsen G, Jahnsen FL. 1998. Cellular and molecular mechanisms for induction of mucosal immunity. Dev Boil Stand Basel Karger 92: 93-108.

2) Kay RA. 1991. Microalgae as food and supplement. Crit Rev Food Sci Nutr 30: 555-573.

3) Ciferri O. 1983. Spirulina: The edible microorganism. Microbiol Rev 47: 551-578.

4) Belay A. 2002. The potential application of Spirulina (Arthrospira) as a nutritional and therapeutic supplement in health management. J Am Nutraceutical Assoc 5: $27-48$.

5) Hayashi O, Hirahashi T, Katoh T, Miyajima H, Hirano T, Okuwaki Y. 1998. Class specific influence of dietary Spirulina platensis on antibody production in mice. I Nutr Sci Vitaminol 44: 841-851.

6) Hayashi O, Katoh T, Okuwaki Y. 1994. Enhancement of antibody production in mice by dietary Spirulina platensis. J Nutr Sci Vitaminol 40: 431-441.

7) Hayashi T, Hayashi K. 1996. Calcium spirulan, an inhibitor of enveloped virus replication, from a bluegreen alga, Spirulina platensis. J Nat Prod 59: 83-87.

8) Mishima T, Murata J, Toyoshima M, Fujii H, Nakajima M, Hayashi T, Kato T, Saiki I. 1998. Inhibition of tumor invasion and metastasis by calcium spirulan (Ca-Sp), a novel sulfated polysaccharide derived from a blue-green alga, Spirulina platensis. Clin Exp Metastasis 16: 541550.

9) Nemoto-Kawamura C, Ishii K, Miyajima H, Hirahashi T, Katoh T, Hayashi O. 2003. Effects of Spirulina phycocyanin ingestion on the mucosal antibody responses in mice. J Phys Fit Nutr Immunol 13: 102-111 (abstract in English).

10) Eldridge JH, Hammond CJ, Meulbroek JA, Staas JK, Gilley RM, Tice TR. 1990. Controlled vaccine release in the gut-associated lymphoid tissues. I. Orally administered biodegradable microspheres target the Peyer's patches. J Controlled Release 11: 205-214.

11) Challacombe SJ, Rahman D, Jeffery H, Davis SS, O'Hagan DT. 1992. Enhanced secretory IgA and sys- temic IgG1 antibody responses after oral immunization with biodegradable microparticles containing antigen. Immunology 76: 164-168.

12) Challacombe SJ, Rahman D, O'Hagan DT. 1997. Salivary, gut, vaginal and nasal antibody responses after oral immunization with biodegradable microparticles. Vaccine 15: 169-175.

13) Hayashi O, Isobe K, An M, Kato T. 1998. Effects of phytocyanin, one of Spirulina components, on differentiation of human leukemia cell lines, U937 and HL-60. Tairyoku Eiyo Men-ekigakuzasshi (J Phys Fit Nutr Immunol) 8: 194-195 (in Japanese).

14) Jeffery H, Davis SS, O'Hagan DT. 1993. The preparation and characterization of poly(lactide-co-glycolide) microparticles. II. The entrapment of a model protein using a (water-in-oil)-in-water emulsion solvent evaporation technique. Pharm Res 10: 362-368.

15) Takahashi T, Nakagawa E, Nara T, Yajima T, Kuwata T. 1998. Effects of orally ingested Bifidobacterium longum on the mucosal $\operatorname{IgA}$ response of mice to dietary antigens. Biosci Biotechnol Biochem 62: 10-15.

16) Nagai T, Kiyohara H, Munakata K, Shirahata T, Sunazuka T, Harigaya Y, Yamada H. 2002. Pinellic acid from the tuber of Pinellia ternata Breitenbach as an effective oral adjuvant for nasal influenza vaccine. Int Immunopharmacol 2: 1183-1193.

17) Kataoka H, Tsuda A, Tsuda Y, Baba A, Yoshida H, Hukui H, Nishiguchi M, Tanaka K, Semma M. 1998. Establishment and application of the abdominal wall method (AW Methods) for induction and detection of immediate allergy. Jpn J Toxicol Environ Health 44: 277-288 (abstract in English).

18) Uchida T, Goto S. 1994. Oral delivery of poly(lactide-coglycolide) microspheres containing ovalbumin as vaccine formulation: Particle size study. Biol Pharm Bull 17: 1272-1276.

19) Ning $Y$, Nemoto-Kawamura C, Ishii K, Hayashi O. 2003. Age-related change of mouse Peyer's patch in scanning electron-microscopic observation and its relation to mucosal immune response. J Phys Fit Nutr Immunol 13: 90-101(abstract in English).

20) Tokuyama H, Tokuyama Y. 1999. The regulatory effects of all-trans-retinoic acid on isotypes switching: Retinoic acid induces IgA switch rearrangement in cooperation with IL-5 and inhibits IgG1 switching. Cell Immunol 192: $41-47$.

21) Tlaskalova-Hogenova H, Tuckova L, Lodinova-Zadnikova R, Stepankova R, Cukrowska B, Funda DP, Striz I, Kozakova H, Trebichavsky I, Sokol D, Rehakova Z, Sinkora J, Fundova P, Horakova J, Jelinkova L, Sanchez D. 2002. Mucosal immunity: Its role in defense and allergy. Int Arch Allergy Immunol 128: 77-89.

22) Hashiguchi M, Hachimura S, Kaminogawa S. 1998. Cytokines secreted by Peyer's patch T cells and IgA production in intestine. Clin Immunol 30: 1524-1531 (in Japanese).

23) Remirez D, Ledon N, Gonzalez R. 2002. Role of histamine in the inhibitory effects of phycocyanin in experimental models of allergic inflammatory response. Mediators Inflamm 11: 81-85.

24) Romay C, Ledon N, Gonzalez R. 2000. Effects of phycocyanin extract on prostaglandin $\mathrm{E}_{2}$ levels in mouse ear inflammation test. Arzneim.-Forsch./Drug Res 50: 11061109. 